\title{
Acoustic alarms reduce porpoise mortality
}

The most serious danger to dolphins and porpoises around the world is the threat from various forms of gill-net fishing. One potential way to reduce the number of deaths of marine mammals is the use of active acoustic alarms to warn animals about the presence of nets ${ }^{1}$. Until now, acoustic alarms have not been tested in field experiments with sufficient statistical power ${ }^{2}$. Here we describe a field experiment showing that acoustic alarms are effective at reducing the number of deaths of harbour porpoises (Phocoena phocoena) in sink gill-nets.

More than 80,000 small cetaceans are killed annually in coastal waters around the world, and at least two species (Phocoena sinus and Lipotes vexillifer) are in imminent danger of extinction because of fishing activities $^{3}$. The number of documented cetacean population collapses due to fishing activities is probably underestimated because data are not available from most of the developing world, where extensive gillnetting is taking place.

Between 18 October and 15 December 1994, 15 commercial sink gill-net fishers from the coasts of New Hampshire and southern Maine took part in our experiment. Strings of 12 nets were tied together. Each net was roughly $92 \mathrm{~m}$ long and $4 \mathrm{~m}$ deep, and had a stretched mesh size of $15 \mathrm{~cm}$. Whenever possible, the strings were soaked for $24 \mathrm{~h}$ and retrieved daily. Strings were set at least $100 \mathrm{~m}$ apart. Fishing took place on or near Jeffreys Ledge, New Hampshire, in an area closed to commercial sink gill-nets because of previous high incidental catches of harbour porpoises. Each vessel carried an independent observer, who changed vessels regularly throughout the experiment.

We used two visibly identical devices, some of which produced an acoustic alarm and others which were silent. Active devices were equipped with a switch activated by salt water that triggered the alarm on complete immersion so that neither fishermen nor observers knew whether strings had active or control alarms until the net was hauled. Each alarm was coded with a number that allowed us to track battery life, losses, malfunctions and the identity of alarms in the vicinity of porpoise by-catches. Thirteen alarms were placed $92 \mathrm{~m}$ apart, attached to the head rope at the end of each string and at each bridle, where individual nets were attached to each other. Each string had either a complete set of active alarms or a set of control alarms. The choice of active or control alarms for each string was made with a coin-toss the day before the string was retrieved and reset.
Observers carried a new set of dry alarms on board the vessel each day and replaced the alarms on strings of nets as they were retrieved. All alarms were changed on a string each time it was retrieved.

Active alarms emitted a broad-band signal with a fundamental frequency of $10 \mathrm{kHz}$, and a source level of $132 \mathrm{~dB}$ (reference pressure $1 \mu \mathrm{Pa}$, measured at $1 \mathrm{~m}$ ), well within the hearing range of harbour porpoises ${ }^{4}$ and harbour seals ${ }^{5}$. The signal lasted for around $300 \mathrm{~ms}$ and was repeated every $4 \mathrm{~s}$. We chose the sound source levels so the alarms would be audible at $15 \mathrm{~dB}$ above ambient sound levels at $100 \mathrm{~m}$ (the length of one net) and to drop to ambient levels at $300 \mathrm{~m}$. Ambient sound levels in the Jeffreys Ledge area range from 110 to $118 \mathrm{~dB}$.

A total of 421 active and 423 control strings were set in similar locations and water depths with similar soak times. Two harbour porpoises were captured in active strings and 25 in control strings. In six control strings, two porpoises were caught in the same string; in all other cases only a single porpoise was taken. The maximum likelihood estimate of $P$ (the probability of capturing at least one porpoise), was 0.025 for control and 0.0027 for active strings. These values were significantly different $\left(\chi^{2}=15.01, P=0.0001\right)$.

We captured similar quantities of two target species of the fishery (cod (Gadus morhua), $t=-0.43, P=0.66$ and pollock (Pollachius virens), $t=0.23, P=0.82$ ) in control and active strings, as well as other commercial species. Of the non-target species that are important prey for the harbour porpoise, silver hake (Merluccius bilinearis) catches were similar in control and active strings $(t=-1.80, P=0.08)$, whereas Atlantic herring (Clupea harengus) were captured infrequently, but more often in control than active strings $\left(\chi^{2}=23.34\right.$, $P=0.01)$. Seals caused damage to the fish catch with similar frequency in control and active strings. Two harbour seals (Phoca vitulina) were entangled in active strings and a single seal was caught in a control string.

At present we do not understand why the use of alarms produced such a dramatic reduction in porpoise catches. Studies of porpoises in a controlled setting suggest that alarms may alert porpoises to the presence of nets ${ }^{6}$, so that porpoises avoided the alarms and were therefore less likely to become entangled. An alternative hypothesis is that the effect was a result of the behaviour of herring, the primary prey of harbour porpoises in the Gulf of Maine ${ }^{7}$. Post mortem examination showed that 17 of 19 porpoises had food remains in their stomachs. The species found most frequently were Atlantic herring (14 stomachs) and silver hake (10 stomachs). The presence of intact fish, flesh and bones, particularly from herring, indicated that many porpoises had been feeding just before entanglement. Herring were the only fish to show a significant difference in catch rate between active and control strings, with fewer herring taken in strings with active alarms. Clupeoid fishes have an unusual capacity for high-frequency hearing $^{8,9}$ and it is possible that herring reacted to the alarms by avoiding the nets, thus reducing the number of porpoises becoming entangled while attempting to capture prey.

Our acoustic alarms reduced the incidental catch of harbour porpoises in sink gill-nets by an order of magnitude. The use of acoustic alarms would seem to be a promising method of reducing the number of harbour porpoises killed in sink gill-nets in the Gulf of Maine and offers hope for alleviating the bycatch problem for small cetaceans worldwide. Recent attempts to apply our results to local experimental fisheries have not been rigorously controlled, and some have produced mixed results, so the testing of alarms in other situations where odontocetes are threatened by gillnets should proceed with careful experimental design and appropriate controls.

\section{Scott D. Kraus}

New England Aquarium,

Edgerton Research Laboratory, Central Wharf,

Boston, Massachusetts 02110, USA

e-mail:skraus@neaq.org

Andrew J. Read

Duke University Marine Laboratory,

Beaufort, North Carolina 28516, USA

Andrew Solow

Woods Hole Oceanographic Institution,

Woods Hole, Massachusetts 02543, USA

Ken Baldwin

Department of Ocean Engineering,

University of New Hampshire, Durham,

New Hampshire 03824, USA

Trevor Spradlin

Office of Protected Resources,

National Marine Fisheries Service,

Silver Spring, Maryland 20910, USA

Eric Anderson, John Williamson

New Hampshire Commercial Fishermen's

Association, Rye, New Hampshire 03780, USA

R. Barnaby, P. Ruell, K. Gestring and S. Drew facilitated data collection aboard the fishing vessels.

1. Jefferson, T. A. \& Curry, B. Biol. Conserv. 67, 167-183 (1994).

2. Dawson, S. M. Rep. Int. Whaling Commiss. 15, 573-578 (1994).

3. Perrin, W. F., Donovan, G. P. \& Barlow, J. (eds) Rep. Int. Whaling Commiss. Spec. Iss. 15 (1994).

4. Andersen, S. Invest. Cetacea 2, 256-259 (1970).

5. Møhl, B. J. Aud. Res. 8, 27-38 (1968).

6. Kastelein, R. A., Goodson, A. D., Lien, J. \& de Haan, D. in Harbour Porpoises: Laboratory Studies to Reduce Bycatch (eds Nachtigall, P. E., Lien, J., Au, W. W. L. \& Read, A. J.) 157-167 (De Spil, Woerden, 1995).

7. Recchia, C. R. \& Read, A. J. Can. J. Zool. 67, 2140-2146 (1989) 8. Enger, P. S. Comp. Biochem. Physiol. 22, 527-538 (1967). 9. Popper, A. N. \& Platt, C. Nature 280, 832-833 (1979). 